\title{
Research with children and adolescents with chronic disease and their families: barriers and facilitators
}

\begin{abstract}
Chronic diseases represent a high cost, requiring adaptations and an efficient health system. On child health, little has been invested in the production of new knowledge. This article purposes to describe the experience of some researchers from a reference center in the care of rare diseases. Research with children and adolescentes requires a playful environment. In addition, it is necessary to understand that the protagonist of the study is the child and the adolescent. The experience of the researchers at the reference center is based on a data collection field inserted in the routine of daily and regular appointments. The waiting room is the great facilitator of the research, with library, games and music, enabling the adherence and participation of both the patient and their guardian. The researchers also use empathy when inviting children and adolescents to participate in the research and privilege the creation of bonds with patients. The child's role in research promotes the need to adapt both the physical space and the approach, which would favor the scarcity of these studies. However, even with these singularities, research on chronic pediatric patients is important, given the relevance of these patients' participation in the health sector budget, both in national and international settings.
\end{abstract}

Keywords: chronic diseases, child, adolescents, researcher-subject relations
Volume 4 Issue 6 - 2020

\author{
Nelbe Nesi Santana,' Rafaella Lima Ferreira \\ Costa, ${ }^{2}$ Aline Pionório Omena, ${ }^{3}$ Cláudia \\ Dayube Pereira ${ }^{4}$ \\ 'Coordinator of the respiratory physiotherapy outpatient clinic \\ of the National Institute of Health for Women, Children and \\ Adolescents Fernandes Figueira, Fiocruz, Brazil \\ ${ }^{2}$ Resident physiotherapist at the National Institute of Health of \\ Women, Children and Adolescents Fernandes Figueira, Fiocruz, \\ Brazil \\ ${ }^{3}$ Physiotherapist at the National Institute of Health of Women, \\ Children and Adolescents Fernandes Figueira, Fiocruz, Brazil \\ ${ }^{4}$ Nurse at the National Institute of Health of Women, Children \\ and Adolescents Fernandes Figueira, Fiocruz, Brazil
}

\begin{abstract}
Correspondence: Nelbe Nesi Santana, Coordinator of the respiratory physiotherapy outpatient clinic of the National Institute of Health for Women, Children and Adolescents Fernandes Figueira / Fiocruz, Av. Rui Barbosa, 716, Flamengo, Rio de Janeiro, RJ, Brazil, CEP: 22250-020, Tel +55 21 25541930, Email nelenesi@iff.fiocruz.br
\end{abstract}

Received: July 30, 2020 | Published: December 30, 2020

\section{Introduction}

Chronic diseases represent a high cost for patients and their families, requiring adaptations and an efficient health system. In addition, children with chronic diseases, even if rare, represent an overload for the Unified Health System (SUS) through their hospital expenses. ${ }^{1}$ Therefore, research on these pathologies is necessary, since their results contribute to the improvement of symptoms, survival and quality of life of these patients, consequently reducing expenses with these individuals. However, the Brazilian literature that systematizes the patterns of use of technologies and medical costs is still scarce., ${ }^{2,3}$ On child health, little has been invested in the production of new knowledge. ${ }^{4}$ In recent years, in general, pediatric treatments are based on personal experiences, case reports, expert recommendations or small clinical trials that cannot be generalized to many children. Thus, researchers and ethics committees are exposed to a double challenge, that of ensuring the right of children to access randomized studies and, at the same time, ensuring that research risks are minimized. Another issue is the difficulty in recruiting children to participate in clinical studies, sometimes due to the reluctance of parents and sometimes due to the low prevalence of a certain clinical condition at a given age. In addition to these reasons, the scarcity of investments in these researches makes it difficult to carry out studies in this age group, which also hinders the training of new researchers and the necessary technical support for current ones. ${ }^{5}$

Research is an essential tool in the search for options for health prevention and treatment, with the objective of ensuring scientific and technological development for the benefit of human beings. ${ }^{6}$ To guarantee the agreement to participate in the research, the research subject needs to read, understand and sign the informed consent form
(ICF). The ICF is a document recommended for use in daily health practice and for conducting research involving human beings. In Brazil, the expression "Free and Informed Consent Term" is adopted, as contained in Resolution 196/96 of the National Health Council. ${ }^{6,7}$ The main challenge during the consent process is to ensure an adequate understanding of the individual, especially in a country where the vast majority of research subjects are extremely vulnerable due to social, cultural and economic conditions. ${ }^{8}$ This barrier is aggravated in pediatric research, as caregivers are responsible for consenting the child's or adolescent's participation in the study. The purpose of this article is to describe the experience of some researchers from a reference center in the care of rare diseases in the state of Rio de Janeiro, Brazil.

\section{Field research}

Research with children and adolescents requires a specific data collection field, where questions and assessments are carried out together with games in a playful environment. ${ }^{9}$ Convincing the child to participate in a survey requires more empathy and more flexible conduct. The prevalence of chronic diseases in children is low, even though it is constantly increasing ${ }^{10}$ and often, the same child participates in several studies at the same time. It is then necessary for researchers to come together to minimize the number of approaches. When the studies are similar, a single approach for two or more researches may be possible, always preserving the confidentiality of the data. In addition, the field needs to adapt to the presence of the child or adolescent's caregiver. ${ }^{11}$ Some studies are based on interviews exclusively with participants, without the presence of their guardian. In other studies, caregiver participation is essential. It is up to the researcher to organize the structure of his field of data 
collection for the evaluation of his research subjects, so that there is no bias of external interference. The experience of the researchers at the reference center is based on a data collection field inserted in the routine of daily and regular appointments previously scheduled. The waiting room is the great facilitator of the research, as it contains a library, games and music, enabling the adherence and participation of both the patient and their guardian. In addition, the researchers use a single approach for various researches, optimizing the time spent by families in the hospital.

\section{Research subject in pediatrics}

In pediatric research, it is necessary to understand that the protagonist of the study is the child and the adolescent. Thus, it is necessary to listen to the patient. Sometimes, the collection time needs to be increased so that the child or adolescent can understand, consent and participate in the research. Research needs to provide enough time for the subject to be able to expose their opinions and ideas without feeling just the object of research. In addition, creating a bond and trust between the researcher and the child is essential. This bond will only occur if the researcher shows interest in listening and understanding the child or adolescent. ${ }^{12}$ The researchers in question use empathy when inviting children and adolescents to participate in the research and privilege the creation of bonds with patients, as well as with caregivers. Participation is voluntary and the research subject can withdraw from research at any time, always preserving their autonomy. Additionally, the researchers offer feedback on the research, through examination reports and presentation of results. Thus, families are able to understand the real reason for the study and the benefits it offers to the population.

\section{Family participation in research with children and adolescents}

Family members have the role of caring for and protecting children and adolescents who are in their care. As a result, barriers or facilitating actions may arise on the part of family members in collecting data from research subjects. Some family members yearn for the research to know the importance and benefits that the study will promote in the treatment of the disease. Therefore, the guardians become great facilitators for researchers in obtaining trust and bond with the child. However, this assistance can sometimes interfere to the point of creating bias in data collection. There are family members who, believing that they are doing the best for the child under their responsibility, refuse to participate in the studies proposed because they are unaware of the research in its entirety and of the benefits it may bring to the evolution of the treatment. Many have fears and anxieties about what research may do to their children. Thus, the guardians refuse to grant the children's participation in the research. Some family members also refuse to participate in the research because they find it tiring and expensive, since the majority of this population lives far from the reference center and because they already have a routine of care that requires a daily expenditure of time. ${ }^{13}$

\section{Conclusion}

The child's role in research promotes the need to adapt both the physical space and the approach, which would favor the scarcity of these studies. However, even with these singularities, research on chronic pediatric patients is important, given the relevance of these patients' participation in the health sector budget, both in national and international settings.

\section{Acknowledgments}

None.

\section{Conflicts of interest}

The author declares there is no conflcit of interest.

\section{References}

1. Pinto Márcia, Romeu Gomes, Roberta Falcão Tanabe, et al. Análise de custo da assistência de crianças e adolescentes com condições crônicas complexas. Ciência \& Saúde Coletiva. 2019;24:4043-4052.

2. Burns KH, Casey PH, Lyle RE, et al. Increasing prevalence of medically complex children in US hospitals. Pediatrics. 2010;126(4):638-646.

3. Leite MF, Gomes IP, Leite MF, et al. Condição crônica na infância durante a hospitalização: sofrimento do cuidador familiar.Cien Cuid Saude. 2012;11(1):51-57.

4. Shaul PW. The cold, hard truth about pediatric research. Pediatric Research. 2007;61:506-509.

5. Martinez-Castaldi C, Silverstein M, Bauchner H. Child versus adult research: the gap in high quality study design. Pediatrics. 2008;122(1):5257.

6. Declaration of Helsinki. Ethical principles for medical research involving human subjects. Adopted by the $18^{\text {th }}$ World Medical Assembly. Helsinki, Finland, June 1964 and amended by 1975, 1983, 1989, 1996. 2000.

7. Brasil. Conselho Nacional de Saúde. Resolução no 196 de 10 de outubro de 1996. Diretrizes e normas reglamentadoras de pesquisas envolvendo seres humanos. Diário Oficial da República Federativa do Brasil, Brasília (DF); 1996

8. Clotet J, Goldim JR, Francisconi CF. Consentimento Informado e a sua prática na assistência e pesquisa no Brasil. Porto Alegre: EDIPUCRS; 2000 .

9. Mitre, Rosa Maria de Araújo, and Romeu Gomes. A promoção do brincar no contexto da hospitalização infantil como ação de saúde. Ciência \& Saúde Coletiva. 2004;9:147-154.

10. Moura EC, Menezes L A, Ferreira IA, et al. Complex chronic conditions in children and adolescents: hospitalizations in Brazil, 2013. Cien Saúde Colet. 2017;22(8):2727-2734.

11. Campos, Daniel de Souza, Martha Cristina Nunes Moreira, et al. Navegando em águas raras: notas de uma pesquisa com famílias de crianças e adolescentes vivendo com doenças raras. Ciência \& Saúde Coletiva. 2020;25:421-428.

12. Neiva-Silva, Lucas, Carolina Lisboa. Bioética na pesquisa com crianças e adolescentes em situação de risco: dilemas sobre. DST-J Bras Doenças Sex Transm. 2005;17(3):201-206.

13. Grossoehme, Daniel H, Stephanie Spear Filigno, et al. Parent routines for managing cystic fibrosis in children. Journal of clinical psychology in medical settings. 2020;21(2):125-135. 